\title{
Interfacial Dislocations and Deformation Twinning in Fully Lamellar TiAl
}

\author{
L.M. Hsiung, B.W. Choi, T.G. Nieh
}

This article was submitted to

$5^{\text {th }}$ International Conference on Structural and Functional Intermetallics, Vancouver, British Columbia, Canada July $16-20,2000$

\section{July 13, 2000}

U.S. Department of Energy

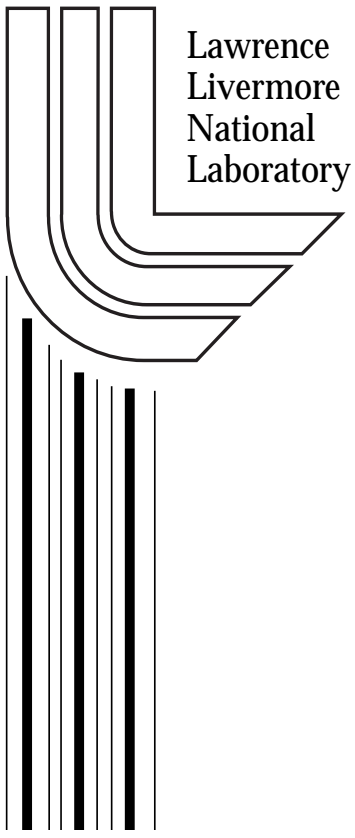




\section{DISCLAIMER}

This document was prepared as an account of work sponsored by an agency of the United States Government. Neither the United States Government nor the University of California nor any of their employees, makes any warranty, express or implied, or assumes any legal liability or responsibility for the accuracy, completeness, or usefulness of any information, apparatus, product, or process disclosed, or represents that its use would not infringe privately owned rights. Reference herein to any specific commercial product, process, or service by trade name, trademark, manufacturer, or otherwise, does not necessarily constitute or imply its endorsement, recommendation, or favoring by the United States Government or the University of California. The views and opinions of authors expressed herein do not necessarily state or reflect those of the United States Government or the University of California, and shall not be used for advertising or product endorsement purposes.

This is a preprint of a paper intended for publication in a journal or proceedings. Since changes may be made before publication, this preprint is made available with the understanding that it will not be cited or reproduced without the permission of the author.

This report has been reproduced directly from the best available copy.

Available to DOE and DOE contractors from the

Office of Scientific and Technical Information

P.O. Box 62, Oak Ridge, TN 37831

Prices available from (423) 576-8401

http:/ / apollo.osti.gov/bridge/

Available to the public from the National Technical Information Service

U.S. Department of Commerce 5285 Port Royal Rd., Springfield, VA 22161 http://www.ntis.gov/

OR

Lawrence Livermore National Laboratory Technical Information Department's Digital Library http://www.llnl.gov/tid/Library.html 


\title{
INTERFACIAL DISLOCATIONS AND DEFORMATION TWINNING IN FULLY LAMELLAR TIAI
}

\author{
L. M. Hsiung, B. W. Choi and T. G. Nieh \\ University of California, Lawrence Livermore National Laboratory \\ Chemistry and Materials Science Directorate \\ L-369, P.O. Box 808, Livermore, CA 94551-9900
}

\begin{abstract}
Deformation twinning, which takes place abnormally within lamellar TiAl subjected to creep deformation at strain rates as low as $10^{-7}$, has been found to be intimately related to the motion, pileup and dissociation of interfacial (Shockley partial) dislocations. In this study, results of in-situ TEM observations are presented to verify the motion and pileup of interfacial dislocations. Since the interfacial (Shockley partial) dislocations are energetically unfavorable to undergo cross-slip or climb, under normal conditions they can only move conservatively along interfaces. Consequently, the pileup configuration once generated cannot be easily dissipated and thus remain in place even at elevated temperatures. The dislocation pileup eventually leads to the emission of deformation twins from the interfaces into $\gamma$ lamellae when a local stress concentration due to the dislocation pileup becomes so great. Deformation twinning of $\{111\}<11 \overline{2}>-$ and $\{11 \overline{2}\}<111>$-type (both generate $\Sigma 3$ twin boundaries) have been observed. Both types of twinning can be rationalized by dislocation mechanisms involving the core dissociation of interfacial dislocations: $1 / 6\left[\overline{1} \overline{2}_{\overline{1}}\right]_{(111)} \rightarrow 1 / 6[011]_{(100)}+1 / 6[\overline{1} 1 \overline{2}]_{\left(\overline{1}_{11}\right)}$

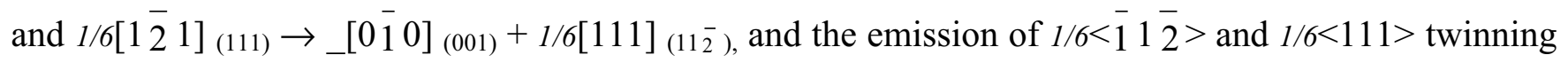
dislocations into $\gamma$ lamellae to form the $(\overline{1} 11)[\overline{1} 1 \overline{2}]$ - and $(11 \overline{2})[111]$-type twins, respectively. The critical shear stress for the $\{111\}<11 \overline{2}>$-type twinning is evaluated using Peach-Koehler formula based upon the pileup configuration of interfacial dislocations.
\end{abstract}

\section{Introduction}

Two-phase lamellar TiAl alloys with $\gamma(\mathrm{TiAl})$ and $\alpha_{2}\left(\mathrm{Ti}_{3} \mathrm{Al}\right)$ phases presented as alternating layers are appealing for applications in advanced turbine engine components because of their high specific 
strength, stiffness, creep resistance and environmental resistance at elevated temperatures. However, a major draw back for the structural applications of the material is their inadequate fracture resistance (ductility and toughness) at low temperatures. To overcome this obstacle, a recent development of the material has focused on refining the $\gamma / \alpha_{2}$ lamellar microstructure through advanced processing routes such as a powder metallurgy (PM) process. The creep properties as well as room-temperature ductility of PM TiAl with a refined lamellar microstructure by introducing more lamellar interfaces to the material have been demonstrated to be superior to those of TiAl fabricated by conventional processing techniques such as ingot metallurgy (IM) which contains relatively coarser microstructures [1-3]. These results invite the need of investigation on the structure-property relationships of refined lamellarTiAl in order to understand the deformation mechanisms as well as the role of lamellar interface in deformation behavior of the material.

One of the unique deformation substructures of two-phase lamellar TiAl is the formation of deformation (mechanical) twins with the thickness in the sub-micrometer region [4-7]. The twinning phenomena have been observed in lamellar TiAl under different testing conditions: tension, creep, and shock deformation. In addition, the creep resistance of lamellar TiAl can be significantly enhanced by deformation twinning via prestraining [8]. That is, when a specimen is first crept to a few percent of strain to form deformation twins at a high stress level, the specimen become more resistant to a subsequent creep deformation at a lower stress level. Although the twinning mechanisms remain to be clarified, it is known that the twinning phenomena become more pronounced within lamellar TiAl with a refined lamellar microstructure. In addition to the stress and orientation dependency of deformation twinning, one of the most important characteristics of twinning phenomena in lamellar TiAl that twinning can take place at elevated temperatures when samples were crept under low strain rates, and the volume fraction of twins increases with cumulative strain. This is unique to the twinning 
phenomena observed in conventional metals and alloys where deformation twinning is more likely to occur under the low-temperature and high strain-rate conditions [9].

A physical model to rationalize the twinning phenomena in lamellar TiAl is currently lacking. It has been proposed previously that the $\{111\}<112>$-type deformation twins can be nucleated from lamellar interfaces by a stair-rod cross-slip mechanism [10], here we provide further the experimental evidence to support the "interface-activated" deformation twinning in order to better understand the role of lamellar interfaces and the interfacial dislocations in twinning as well as deformation behavior of lamellar TiAl.

\section{Experimental}

A two-phase lamellar TiAl alloy with a nominal composition of Ti-47Al-2Cr-2Nb (at. \%) was fabricated by a powder metallurgy process, which involves a hot-extrusion of gas-atomized titanium aluminide powder at $1400^{\circ} \mathrm{C}$. A refined fully lamellar microstructure ( $\gamma$ lamellae: $100 \sim 300 \mathrm{~nm}$ thick, and $\alpha_{2}$ lamellae: $10 \sim 50 \mathrm{~nm}$ thick) was formed within the alloy [7]. After extrusion, the alloy was stress-relieved at $900^{\circ} \mathrm{C}$ in a vacuum $\left(\sim 10^{-4} \mathrm{~Pa}\right)$ for $2 \mathrm{~h}$. Creep tests were conducted in a dead-load creep machine with a lever arm ratio of 16:1. For current study, the deformation substructures of tested specimens [crept at $760^{\circ} \mathrm{C}, 138 \mathrm{MPa}$ (creep strain: $0.25 \%$ ), $760^{\circ} \mathrm{C}, 518 \mathrm{MPa}$ (creep strain: $3.6 \%$ ), and $815^{\circ} \mathrm{C}, 420 \mathrm{MPa}$ (creep strain: 1.7\%)] were investigated and compared. TEM foils were prepared by twinjet electropolishing in a solution of 60 vol. $\%$ methanol, 35 vol. \% butyl alcohol and 5 vol. \%

perchloric acid at $\sim 15 \mathrm{~V}$ and $-30^{\circ} \mathrm{C}$. The microstructures of the crept alloys were then examined using a JEOL-200CX transmission electron microscope equipped with a double-tilt goniometer stage. Images of dislocations were recorded using a weak-beam dark field (WBDF) imaging technique under $\boldsymbol{g}(3 \boldsymbol{g})$ two-beam diffraction conditions with the deviation factor $\omega\left(=\xi_{g} s\right)>\sim 1$, where $\xi_{g}$ is the extinction distance and $\mathrm{s}$ is the deviation distance from the exact Bragg position. The $\boldsymbol{g} \boldsymbol{\bullet} \boldsymbol{b}$ invisibility criteria used for determining the Burgers vector of Shockley partials are described as follows [11]: (a) Invisible if $\boldsymbol{g} \bullet \boldsymbol{b}$ 
$=0$ or $\pm 1 / 3$. (b) Invisible if $\boldsymbol{g} \cdot \boldsymbol{b}=-2 / 3$ but visible if $\boldsymbol{g} \boldsymbol{b}=+2 / 3$ provided the deviation factor $\omega>\sim 1$. (c) Invisible if $\boldsymbol{g} \cdot \boldsymbol{b}=+4 / 3$ but visible if $\boldsymbol{g} \cdot \boldsymbol{b}=-4 / 3$ provided the deviation factor $\omega>\sim 1$.

\section{Results and Discussion}

\subsection{Twinning phenomena in crept samples}

The creep data obtained from samples tested at 760 and $815^{\circ} \mathrm{C}$ is shown in Fig. 1 (a), which reveals that there exist two distinct low stress $(L S)$ and high stress $(H S)$ creep regimes. In the $L S$ regime (<400 MPa), a nearly linear creep behavior (i.e. $\stackrel{<}{\varepsilon} \sim \sigma^{n}$ and $n \sim 1$ ) is observed, and in the $H S$ regime (> $400 \mathrm{MPa}$ ), a nonlinear creep behavior (i.e. $n \sim 7$ ) is observed. While the linear creep behavior in the $L S$ regime can be rationalized to be due to the viscous glide of interfacial dislocations [7], an explanation for the (high $\mathrm{n}$ ) nonlinear creep behavior (although twinning is known to be the predominant deformation mode) in the $H S$ regime remains to be further explored because of its relative complexity.

Figures 1 (b) and 1 (c) are typical twinning substructures formed within samples crept at $\mathrm{A}\left(760^{\circ} \mathrm{C}, 518\right.$ $\mathrm{MPa}, \varepsilon=3.6 \%)$ and $\mathrm{B}\left(815^{\circ} \mathrm{C}, 420 \mathrm{MPa}, \varepsilon=1.7 \%\right)$, respectively. Here, deformation twins of nanoscale can be clearly seen in Fig. 1 (b). Besides, the twin density is found to be greater within the sample crept under higher stress and creep strain. More evidence for the emission of deformation twins from lamellar interfaces is shown in Figs. 2 (a) and 2 (b), where the nucleation of twin embryos from interfaces were observed within samples crept under different conditions. The observations of chisel- or blade-shape twin embryos support the twinning mechanisms we have proposed previously [7] that twinning process is resulted from a successive dislocation dissociation [ $\mathbf{b}_{\mathbf{1}}$ (interfacial dislocation) $\rightarrow \mathbf{b}_{\mathbf{2}}$ (stair-rod dislocation) $+\mathbf{b}_{\mathbf{3}}$ (twinning dislocation)] and repeated emission of twinning dislocations from interface as illustrated in Fig. 2(c). Since each twinning dislocation is sequentially emitted, the formation of chisel- or blade-shape embryo is anticipated. 


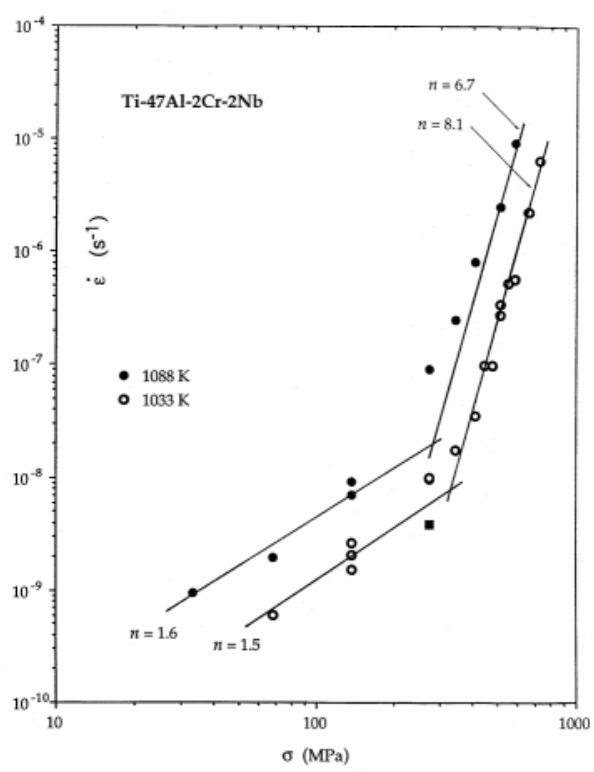

(a)

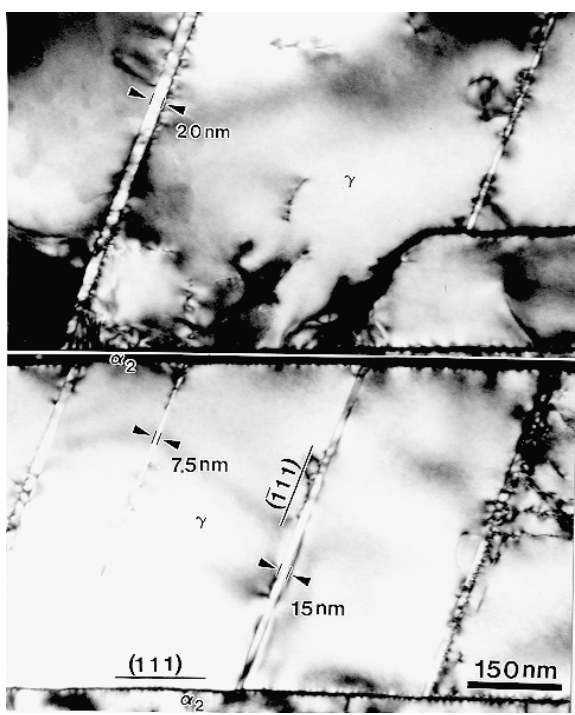

(b)

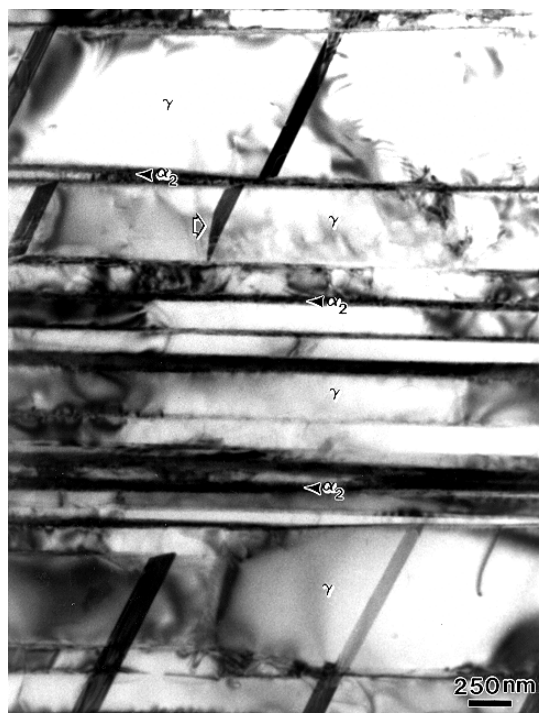

(c)

Fig. 1. (a) Steady-state creep rate plotted as a function of applied stress at 760 and $815^{\circ} \mathrm{C}$. Typical deformation substructures observed from samples crept at (b) $760^{\circ} \mathrm{C}, 518 \mathrm{MPa}$ and (c) $815^{\circ} \mathrm{C}, 420 \mathrm{MPa}$.

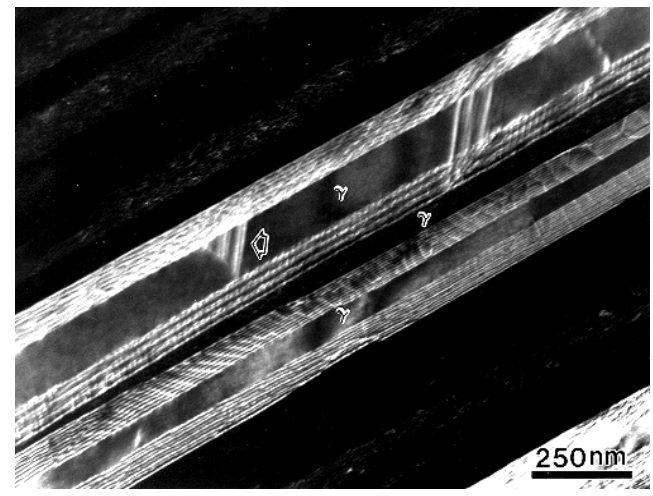

(a)

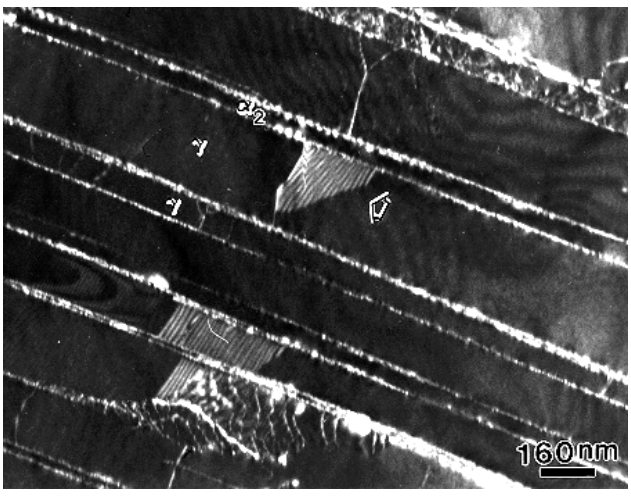

(b)

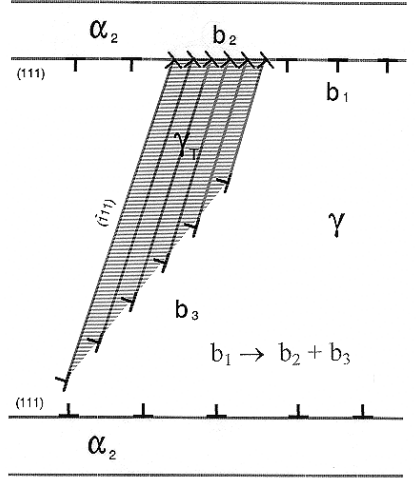

(c)

Fig. 2. TEM images showing the emission of twin embryos (marked by arrows) from lamellar interfaces observed from the samples crept at (a) $760^{\circ} \mathrm{C}, 518 \mathrm{MPa}$ and (b) $815^{\circ} \mathrm{C}, 420 \mathrm{MPa}$.

When creep is conducted in $H S$ regime, the strain accommodation near colony boundary due to the motion of interfacial dislocations (interfacial sliding) becomes less effective as the strain rate increases. This could results in the pileup of interfacial dislocations near the boundary and causing a local stress concentration to build up near the boundary, which may promote the twinning process so as to dissipate 
the local stress concentration. That is, a higher density of deformation twins is likely to form near the colony boundary. A typical example is shown in Fig, 3, where the twin density is greater than that found at location far away from the colony boundary [Fig. 1(b)].

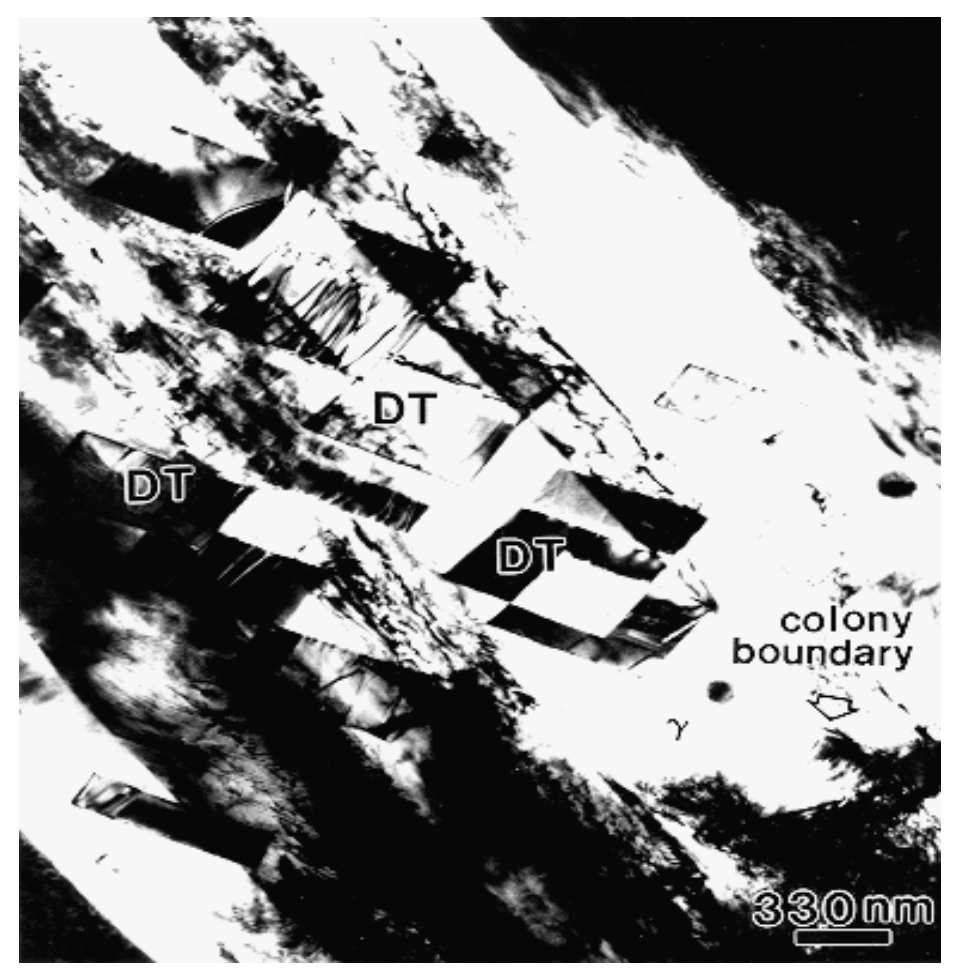

Fig. 3. TEM image taken from a sample crept at $760^{\circ} \mathrm{C}$ and $518 \mathrm{MPa}$ showing the formation of higher density of deformation twins (labeled as DT) near colony boundary.

In addition to the twinning phenomena observed above, the twinning process is also found to be dependent on the orientation of lamellar interface with respect to the stress axis as shown in Fig. 4. Here in the same crept sample, deformation twins were found within both $10^{\circ}$-oriented and $45^{\circ}$-oriented grains but was not found in a $5^{\circ}$-oriented grain. More importantly, instead of the normal $\{111\}<11 \overline{2}>$-type twin as found in the $45^{\circ}$ grain, a $(11 \overline{2})[111]$-type deformation twin was found within the $10^{\circ}$ grain. This is abnormal since it is the twin system most commonly observed in bcc structure, although both the $\{111\}<11 \overline{2}>$ and $\{11 \overline{2}\}<111>$ twin boundaries are belongs to $\Sigma 3$ type according to the coincident site lattice (CSL) concept [12]. More results on the dislocation reactions for the $\{111\}$ and $\{112\}$ twinning are demonstrate below. 
As for the ( $\overline{1} 11)$-type deformation twinning, the corresponding dislocation dissociation reaction is

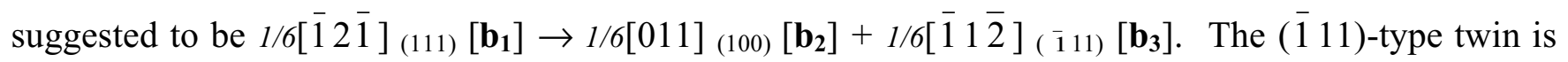
accordingly formed by a successive emission of the twinning dislocations $1 / 6[1 \overline{1} 2]$ on the $(\overline{1} 11)$ plane and leaving the stair-rod dislocations $1 / 6[011]$ on the (100) plane. The evidence of the formation of stairrod dislocations is shown in Fig. 5, where an array of $1 / 6[011]$ stair-rod dislocations become invisible [Fig. 5 (a)] or visible [appeared as sharp-bright contrast in Fig. 5 (b)] when a reflection vector (g) 200 or 021 is used for imaging. It is noted that the individual stair-rod dislocation is not resolvable because of a very narrow distance $(0.25 \mathrm{~nm})$ between the stair-rod dislocations. Similarly, the corresponding dislocation dissociation reaction for the $(11 \overline{2})$-type deformation twinning is suggested to be $1 / 6[1 \overline{2} 1]$ $(111)\left[\mathbf{b}_{1}\right]_{-}$[0 $\left._{10}\right]_{(001)}\left[\mathbf{b}_{2}\right]+1 / 6[111]_{(11 \overline{2})}\left[\mathbf{b}_{3}\right]_{.}$The $(\overline{1} 11)$-type twin is accordingly formed by a successive emission of the twinning dislocations $1 / 6[111]$ on the $(11 \overline{2})$ plane and leaving the stair-rod dislocations $1 / 2[100]$ on the (001) plane. The evidence of the formation of stair-rod dislocations is shown in Fig. 6, where an array of $1 / 2[0 \overline{1} 0]$ stair-rod dislocations become visible [Fig. 6 (a)] or invisible [Fig. 6 (b)] when a reflection vector (g) 020 or 002 is used for imaging.

The above observations suggest that the resolved shear stresses on both lamellar interface [parallel to the (111) plane] and twin plane are critical to the twinning process, the shear stress on interface is necessary to generate the pileup configuration for activating twinning reactions, and the critical shear stress $\left(\tau_{c}\right)$ on twin plane is required to pull the twinning dislocation so as to form the stacking fault (a pair of twin interfaces) on its wake, i.e. $\tau_{c} \approx \gamma_{s f} / 2 b$, where $\gamma_{s f}$ is the stacking fault energy. Although further study is needed to rationalize the $\{112\}$-type twinning, it is postulated here that "interface activated" twinning can be a competing process between the $\{111\}$ - and $\{112\}$-type twinning. The $\{112\}$-type twinning becomes favorable when a lamellar grain is oriented so that the resolved shear stress on $\{111\}$ is smaller than the critical stress required for the $\{111\}$-type twinning, and on the other 
hand the resolved shear stress on $\{112\}$ is greater than the critical stress required for the $\{112\}$-type twinning. Consequently, the orientation of lamellar grain in Fig. 4 (c) promote the dissociation reaction: $1 / 6[1 \overline{2} 1]_{(111)} \rightarrow[0 \overline{1} 0]_{(001)}+1 / 6[111]_{(11 \overline{2})}$ for $\{11 \overline{2}\}$ twinning and prohibit the dissociation reaction: $1 / 6[\overline{1} 2 \overline{1}]_{(111)} \rightarrow 1 / 6[011]_{(100)}+1 / 6[\overline{1} 1 \overline{2}]_{(\overline{1} 11)}$ for $\{111\}$ twinning.

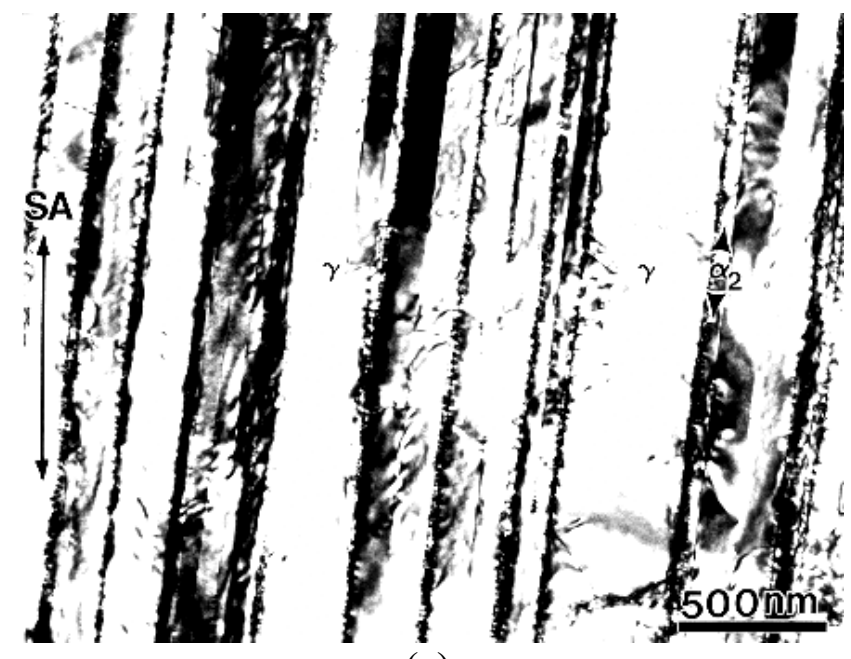

(a)

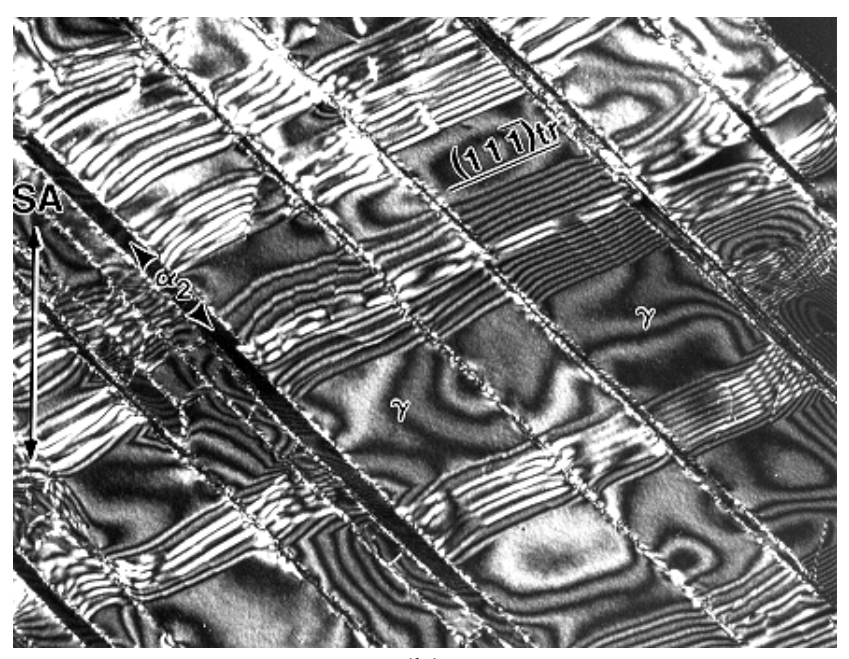

(b)

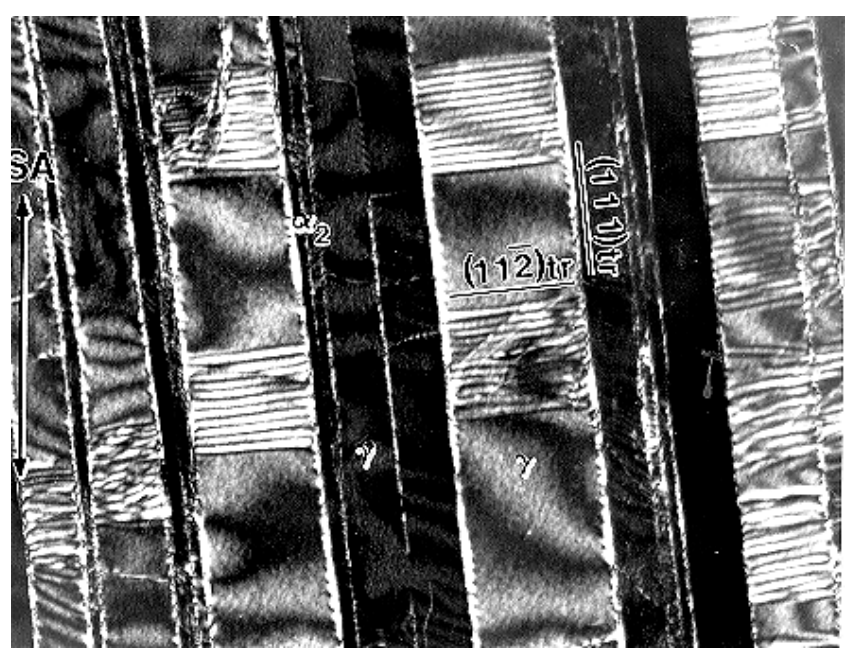

(c)

Fig. 4. TEM images taken from a sample crept at $760^{\circ} \mathrm{C}$ and $518 \mathrm{MPa}$ showing the twinning process is dependent on the orientation (angle) of lamellar interface with respect to the stress axis (SA). (a) No twin formation within a $5^{\circ}$-oriented lamellar grain, (b) the formation of $(\overline{1} 11)$ type twins within a $45^{\circ}$-oriented lamellar grain, (c) the formation of (11 $\overline{2}$ )-type twins within a

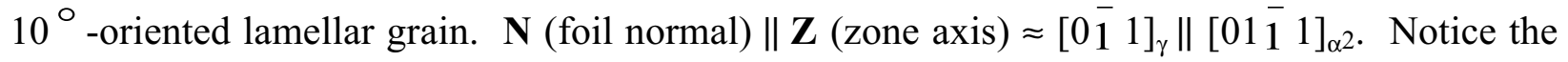
appearance of thickness fringes on every deformation twin located between interfaces. 


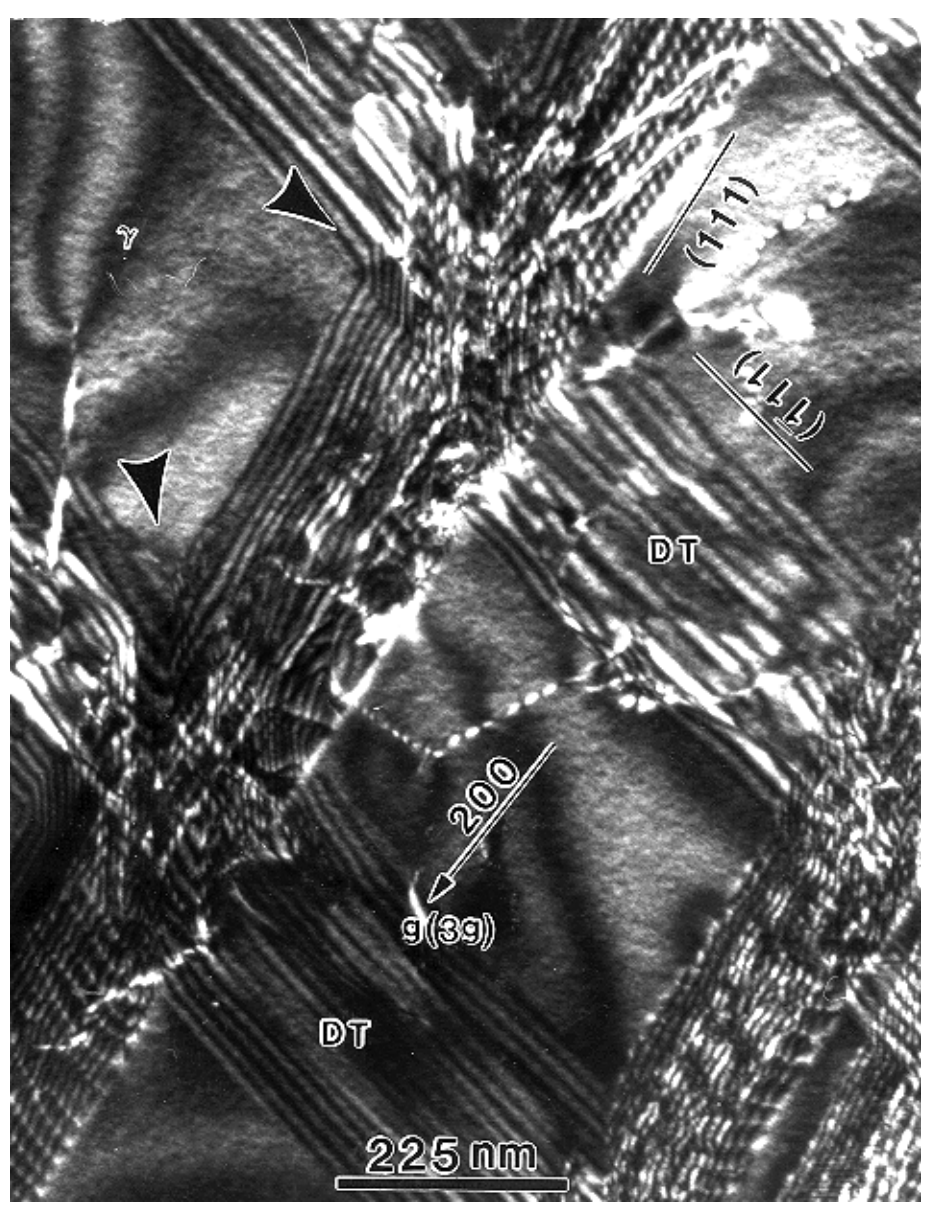

(a)

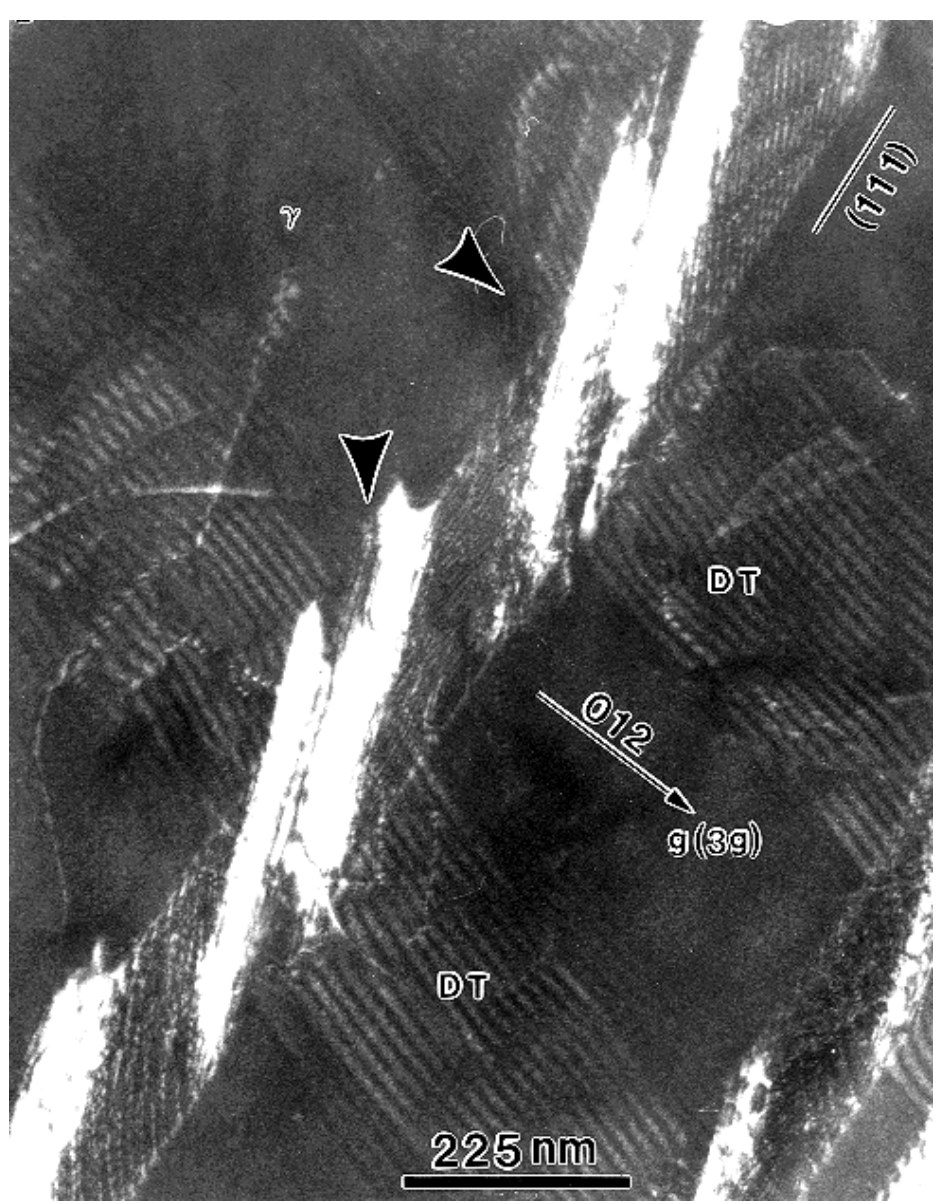

(b)

Fig. 5. Paired WBDF images showing the existence of $1 / 6[011]$ stair-rod dislocation array at the junctions (indicated by arrows) between the (111)-type deformation twin (DT) and $\alpha_{2}$ lamella. (a) Invisible at $\boldsymbol{g}=200(\boldsymbol{g} \bullet \boldsymbol{b}=0),(\mathrm{b})$ visible at $\boldsymbol{g}=012(\boldsymbol{g} \bullet \boldsymbol{b}=\ldots), \mathbf{Z}(\mathrm{zone}$ axis $) \approx[02 \overline{1}]$. 


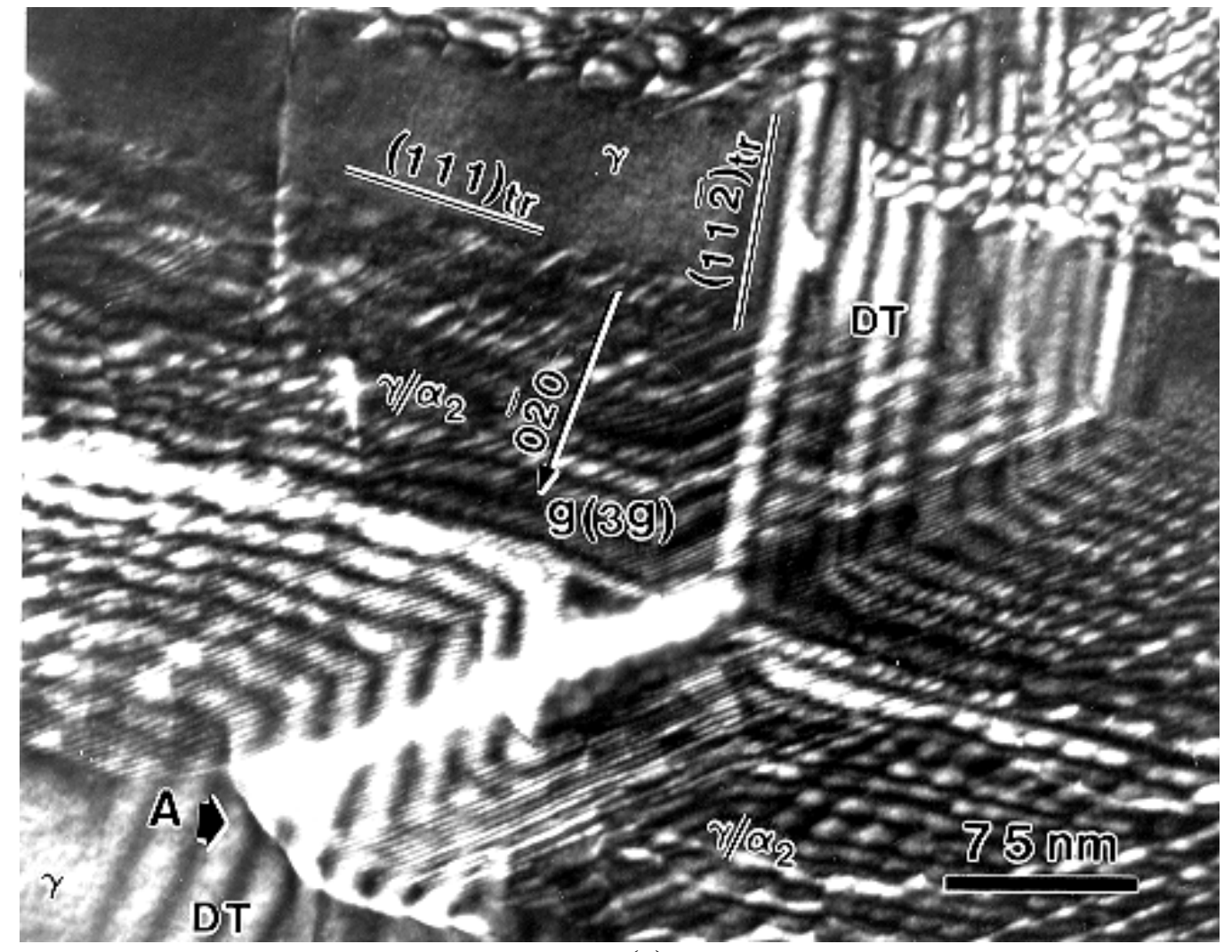

(a)

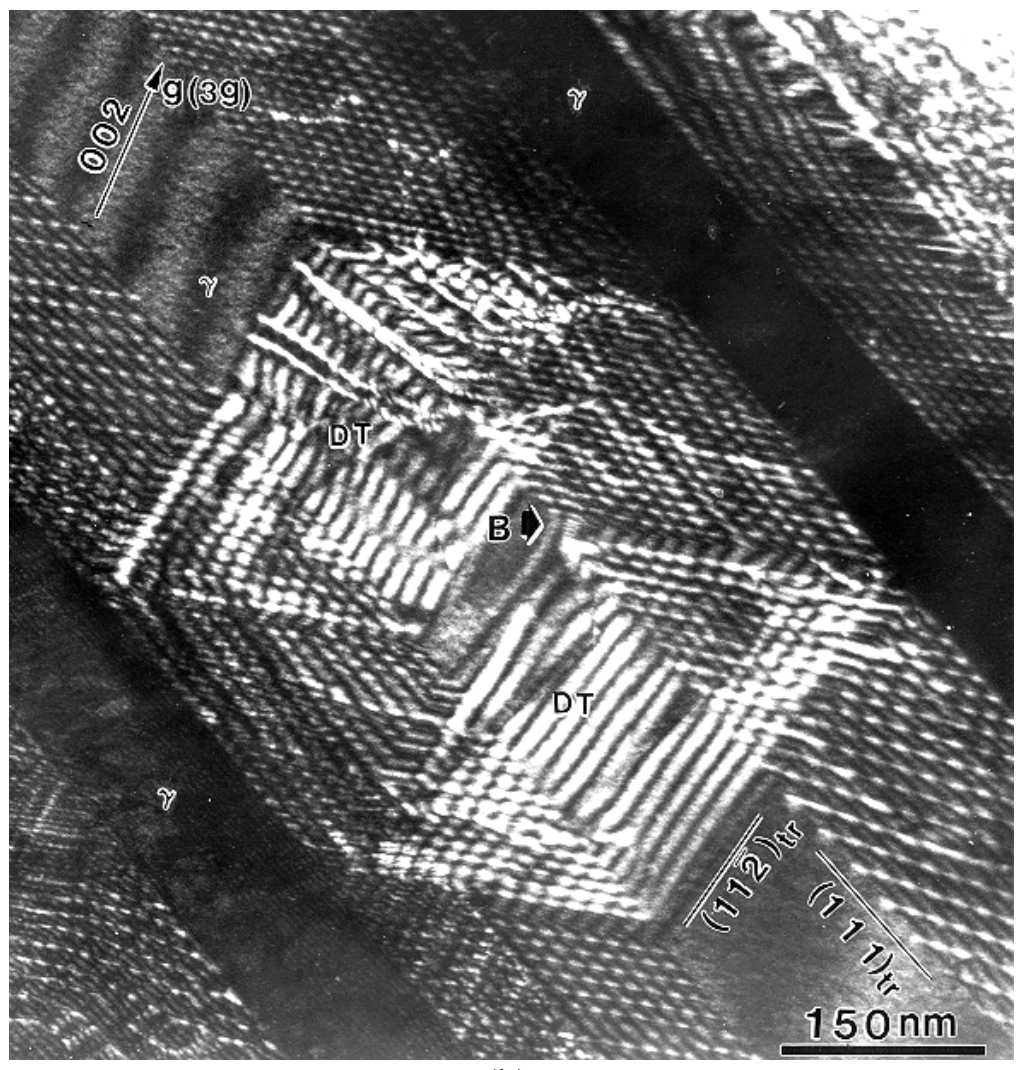

(b)

Fig. 6. WBDF images showing the existence of $1 / 2[0 \overline{1} 0]$ stair-rod dislocation array at the junctions (indicated by arrows) between the (11 $\overline{2})$ type deformation twins (DT) and $\alpha_{2}$ lamella. (a) Visible at $\boldsymbol{g}=0 \overline{2} 0(\boldsymbol{g} \bullet \boldsymbol{b}=1), \mathbf{Z}$ (zone axis) $\approx[304]$, (b) invisible at $\boldsymbol{g}=002(\boldsymbol{g} \bullet \boldsymbol{b}=0), \mathbf{Z}$ (zone axis) $\approx[320]$. 


\subsection{In-situ TEM observations of interfacial dislocation motion and pileup}

Results of in-situ TEM experiment to demonstrate the cooperative motion of interfacial dislocations in lamellar TiAl under room-temperature straining conditions have been reported elsewhere [13]. Here, results of in-situ TEM observations (from a sample pre-crept at $760^{\circ} \mathrm{C}$ and $138 \mathrm{MPa}$ ) are presented in Fig. 7 to demonstrate the motion and pileup of interfacial dislocations under electron-beam heating conditions. Since the purpose the study is solely to demonstrate the direct observations of interfacial dislocation motion, the amount of temperature increase by beam heating is not a major concern. It is also noted that a local heating can be achieved when electron-beam is focused to a small spot size of several micron meters.

Figure 7 (a) shows the cooperative motion of a dislocation array (eight interfacial dislocations) on a $\gamma / \gamma$ interface. Each of the eight dislocations moved about $250 \mathrm{~nm}$ after beam focusing (heating) for 20 seconds. That is, each dislocation moved at roughly the same velocity in this case. Figure 7 (b) shows the motion of interfacial dislocations within a dislocation pileup on a $\gamma / \alpha_{2}$ interface. Here, the head of dislocation pileup is at the tip of $\alpha_{2}$ fragment adjacent to the dislocation labeled \#1. It is seen that the dislocation spacing increases with distance from the pileup tip, and the dislocations close to the pileup tip moves slower than those far away from the tip. For instance, the \#10 and \#20 dislocation moved about $170 \mathrm{~nm}$ and \#35 and \#45 dislocations moved about $250 \mathrm{~nm}$ after beam focusing (heating) for 30 seconds. That is, during beam heating, dislocations in the pileup start to squeeze which causes the increase of dislocation density within the pileup. The above in-situ observations of interfacial dislocation motion and pileup can be explained below.

Since the pre-crept sample contains residual stresses especially at interfaces, interfacial dislocations can start to move or drift under heating according to $v_{\text {dis }}=M F$, where $v_{\text {dis }}$ is the (drift) velocity of dislocation, $M$ is the mobility of interfacial dislocation, and $F$ is the effective force acting on the 
dislocation. An explicit expression for the dislocation mobility $M$ limited by solute drag can be found in [14] is $M=\frac{D_{s} \Omega}{\beta b^{2} C_{o} k T}$, where $\beta$ is a constant, $b$ is the length of Burgers vector, $C_{o}$ is the solute concentration and $D_{s}$ is the solute diffusion coefficient, and $\Omega$ is the atomic volume of solute. For the effective force $(F)$ acting on the $i$-th dislocation in a dislocation array or pileup can be expressed as $F=$

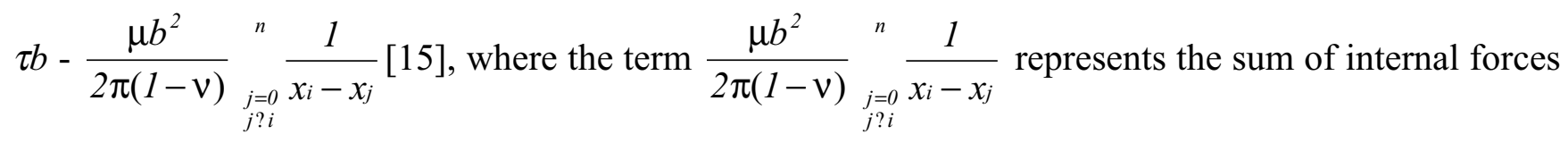
acting on the $i$-th dislocation by the other dislocations of the pileup; $\mathrm{x}_{\mathrm{i}}-\mathrm{x}_{\mathrm{j}}$ represents the distance between the $i$-th and $j$-th dislocations. Accordingly, $v_{d i s}$ increases as a result of the increase of dislocation mobility as temperature $(T)$ increases after beam focusing (heating), and $v_{\text {dis }}$ diminishes as temperature decreases to an ambient temperature after beam spreading. The velocity of dislocations close to the pileup tip becomes slower indicates that the internal stress acting on the dislocations increases as the dislocations move closer to the pileup tip, and therefore reducing the effective force $(F)$ acting on the dislocations. In addition, the effective stress (or local stress) $\tau_{e}$ at the tip (or lead dislocation) of the pileup of $n$ dislocations is $n \tau$ according to Eshelby et al. [17]. 


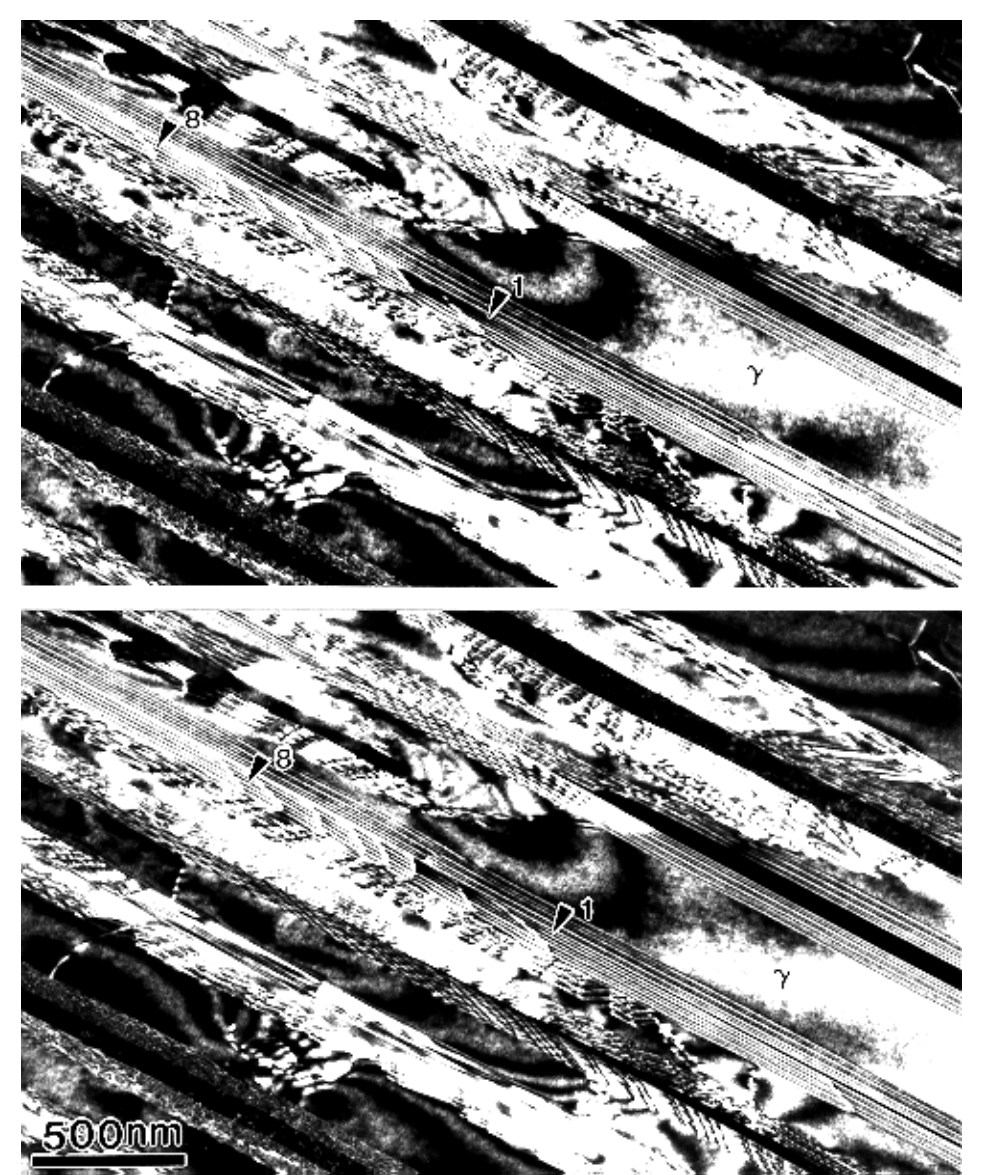

(a)
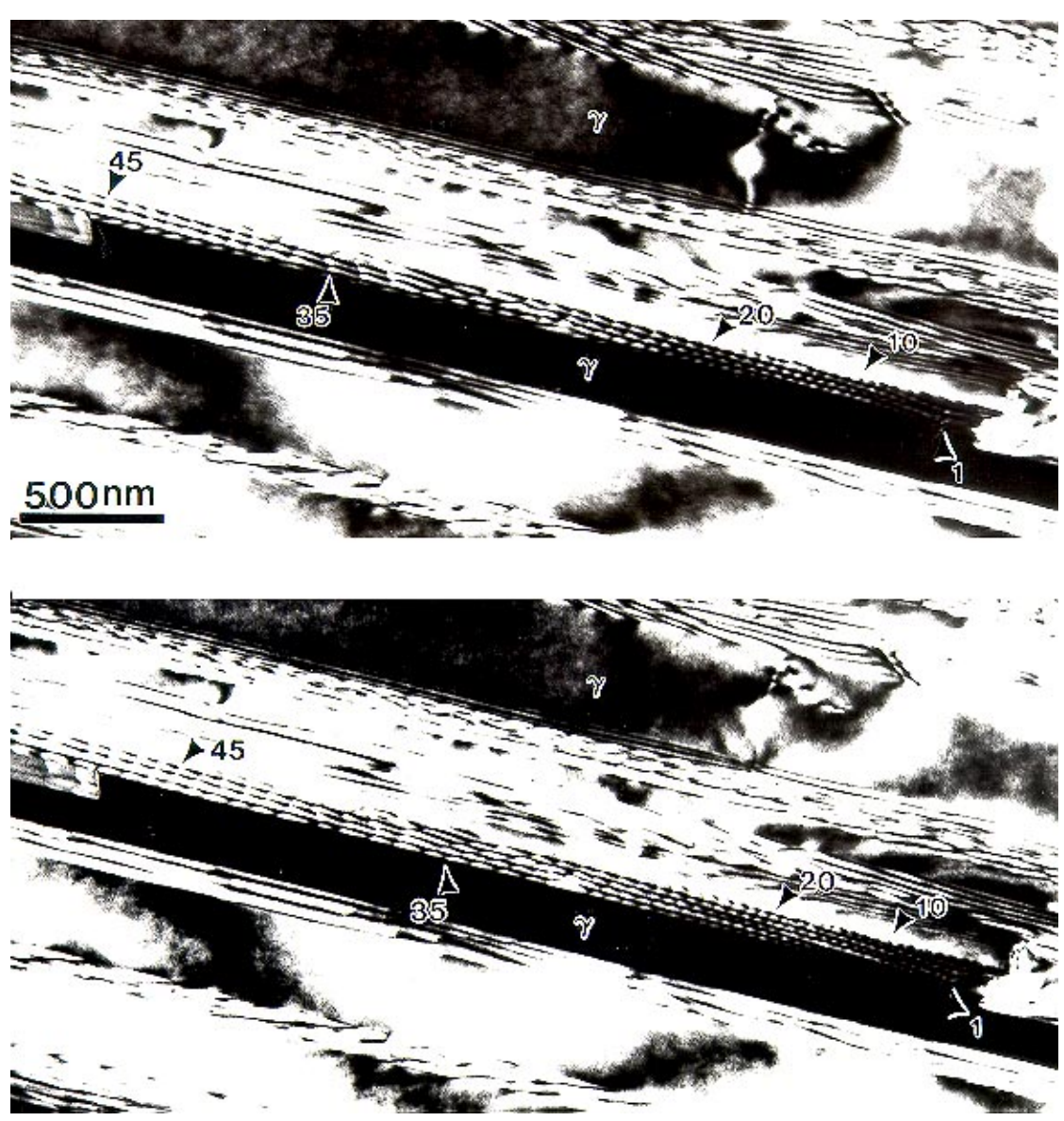

(b)

Fig. 7. Consecutive in-situ TEM images showing (a) the motion of an interfacial dislocation array in a $\gamma / \gamma$ interface (beam heating: $20 \mathrm{~s}$ ), and (b) the motion of interfacial dislocations in a dislocation pileup on a $\gamma / \alpha_{2}$ interface (beam heating: $30 \mathrm{~s}$ ). The head of pileup is at the tip of $\alpha_{2}$ fragment adjacent to the dislocation labeled \#1. 


\subsection{Critical shear stress for the interface-activated (111)[11 $\overline{2}$ ] twinning}

The above TEM observations support that deformation twinning in crept FL-TiAl is activated by the local stress concentration due to the pileup of interfacial dislocations during creep deformation. Since the interfacial (Shockley partial) dislocations are energetically unfavorable to undergo cross-slip or climb, under normal conditions they can only move conservatively along interfaces. Consequently, the pileup configuration once generated cannot be easily dissipated and thus remain in place even at elevated temperatures. The dislocation pileup eventually leads to the emission of deformation twins from the interfaces into $\gamma$ lamellae when a local stress concentration due to the dislocation pileup becomes so great. The significance of the previously proposed twinning mechanisms [10] is to reveal that there are several barriers to be overcome in order to activate the twinning reaction. These barriers include (1) the repulsive force $(F)$ between the interfacial (Shockley) and stair-rod dislocations, (2) the increase of line energy due to the dislocation dissociation, and (3) the increase of interfacial energy due to the formation of twin faults. Among them the repulsive force $(F)$ between the interfacial (Shockley) and stair-rod dislocations is considered to be rate controlling. That is, a minimum shear stress for "interface-activated" twinning will be the critical stress $\left(\tau_{c}\right)$ required to activate the dissociation

reaction [as for example of the $(\overline{\mathbf{1}} 11)$-type twinning]: $\left.1 / 6[\overline{1} 2 \overline{1}]_{(111)} \rightarrow 1 / 6[011]_{(100)}+1 / 6[\overline{1} 1 \overline{2}]_{\left({ }_{1}\right.} 11\right)$. This can be evaluated using Peach-Koehler formula based upon the pileup configuration of interfacial dislocations illustrated in Fig. 8.

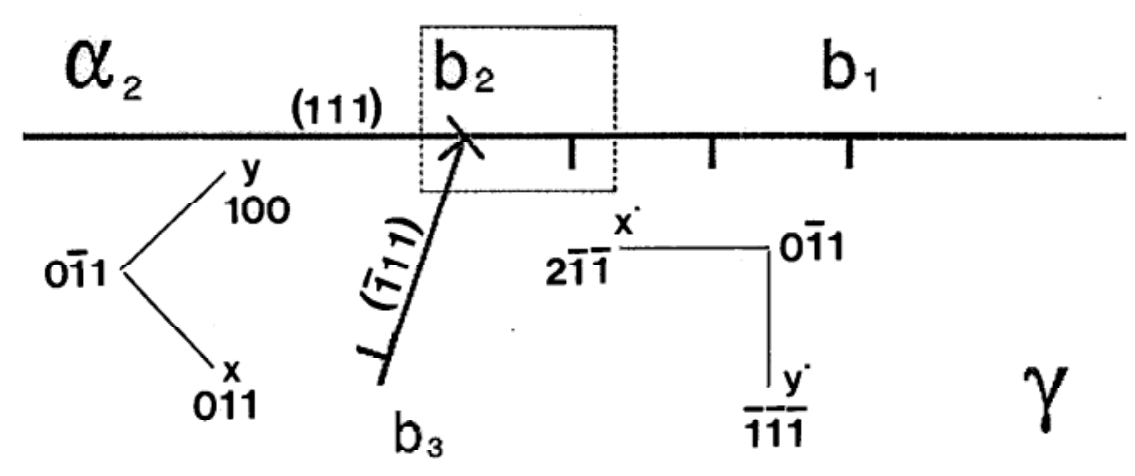

Fig. 8. A schematic illustration shows a dislocation pileup configuration on a $\gamma / \alpha_{2}$ interface. $\mathbf{b}_{1}$ $(1 / 6[\overline{1} \overline{2} \overline{1}]), \mathbf{b}_{2}(1 / 6[011])$ and $\mathbf{b}_{3}(1 / 6[\overline{1} 1 \overline{2}])$ respectively, stand for interfacial, stair-rod, and twinning dislocation. Line vectors of the three dislocations are all parallel to the $<0 \overline{1} 1>$ direction. 
Assuming an isotropic elasticity, the critical stress can be approximately evaluated using Peach-Koehler formula:

$$
\begin{aligned}
& \overrightarrow{\mathbf{F}} \quad=\left|\begin{array}{ccc}
\sigma_{\mathbf{x x}} & \sigma_{\mathrm{xy}} & 0 \\
\sigma_{\mathbf{y x}} & \sigma_{\mathrm{yy}} & 0 \\
0 & 0 & \sigma_{\mathrm{zz}}
\end{array}\right| \begin{array}{lll}
\mathbf{b}_{1} & \cos \theta_{2} & \mathrm{x} \\
& \cos \theta_{3} &
\end{array} \\
& \overrightarrow{\mathbf{F}} \quad=\mathbf{b}_{1}\left|\begin{array}{ccc}
\mathbf{i} & \mathbf{j} & \mathbf{k} \\
0.5 \sigma_{\mathrm{xx}} & 0.5 \sigma_{\mathrm{yx}} & 0.87 \sigma_{\mathrm{zz}} \\
0 & 0 & 1
\end{array}\right|
\end{aligned}
$$

Since the stair-rod dislocation $\left(\mathbf{b}_{2}\right)$ is pure edge in character, the elastic stresses about the stair-rod dislocation are:

$$
\begin{aligned}
& \sigma_{\mathrm{xx}}=\frac{\mu \mathbf{b}_{2}}{2 \pi(1-v)} \frac{\mathbf{y}\left(3 \mathbf{x}^{2}+\mathbf{y}^{2}\right)}{\left(\mathbf{x}^{2}+\mathbf{y}^{2}\right)^{2}}, \quad \sigma_{\mathrm{yx}}=\frac{-\mu \mathbf{b}_{2}}{2 \pi(1-v)} \frac{\mathbf{x}\left(\mathbf{x}^{2}+\mathbf{y}^{2}\right)}{\left(\mathbf{x}^{2}+\mathbf{y}^{2}\right)^{2}}, \quad \sigma_{\mathrm{zz}}=\frac{\mu v \mathbf{b}_{2} \mathbf{y}}{\pi(1-v)\left(\mathbf{x}^{2}+\mathbf{y}^{2}\right)} \\
& \text { where, } y=a_{12} x^{\prime}+a_{22} y^{\prime}, x=a_{11} x^{\prime}+a_{21} y^{\prime} \text {, and } a_{11}=a_{22}=\cos 54.4^{\circ}, a_{12}=\cos 144.44^{\circ} \\
& \text { and } a_{21}=\cos 35.56^{\circ} \text {. } \\
& \text { Thus, } \\
& \tau_{c} b_{1}=b_{1}\left(0.5 \sigma_{y x}\right), \tau_{c}=1.02 \mu b_{2} / 2 \pi(1-v) .
\end{aligned}
$$

Where $\mu\left(\sim 56 \mathrm{GPa}\right.$ at $\left.760^{\circ} \mathrm{C}[16]\right)$ is the shear modulus, $b_{1}(\sim 0.163 \mathrm{~nm})$ and $b_{2}(\sim 0.094 \mathrm{~nm})$ are the length of Burgers vectors of Shockley and stair-rod dislocations, and $\mathrm{x}^{\prime}(=0.4 \mathrm{~nm})$ and $\mathrm{y}^{\prime}(=0.46 \mathrm{~nm})$ are the distance between dislocations in the $\mathrm{x}^{\prime}-\mathrm{y}^{\prime}$ axes. The critical stress $\left(\tau_{c}\right)$ is estimated to be 1.28 GPa.

In the case of a low applied stress $(138 \mathrm{MPa})$ and small creep strain, the resolved shear stress $\left(\tau_{i}\right)$ acting on the interface plane is about $69 \mathrm{MPa}$ (for Schmid factor $=0.5)$, the number $(n \sim 20)$ of pileup dislocations required to create a high enough effective stress (i.e. $\tau_{e}=n \tau_{i}$ [17]) is large. Consequently, the formation of deformation twins under low stress and low strain is less likely. In the case of a high applied stress (518 MPa), shear stress acting on the interface plane is about $259 \mathrm{MPa}$ (using Schmid factor 0.5). This value is much greater than $69 \mathrm{MPa}$ for the case of low applied stress, the number $(n \sim$ 6) of pileup dislocations, thus accumulation creep strain required to nucleate deformation twins becomes much easier to reach. A recent investigation on the formation of deformation twins in lamellar TiAl 
creep-deformed at different loading conditions [18] has further support the above viewpoint. That is, deformation twins started to form within samples loaded at $138 \mathrm{MPa}$ level when the accumulation creepstrain became large (1.5\%). In addition, the volume fraction and thickness of deformation twin were found to increase with increasing accumulation creep-strain.

\section{Conclusion}

Twinning phenomena and the role of interfacial dislocations in deformation twinning of lamellar TiAl have been investigated. In addition to the stress and orientation dependency of deformation twinning, several other characteristics of twinning phenomena are identified as below. (1) Twin embryos of blade-shape are found to nucleate from lamellar interfaces. (2) The thickness of deformation twin is in a range of several to several tens nanometers. (3) Density of twin lamellae near to colony boundary is usually greater. (4) Twinning can take place at elevated temperatures under very low creep strain-rates, which is unique to the twinning phenomena found in conventional metals and alloys where deformation twinning are more likely to occur under the low-temperature and high strainrate conditions. The twinning mechanisms are further verified to be a stress relaxation process for the local stress concentration at the tip of interfacial dislocation pileup. Deformation twinning of $\{111\}<11 \overline{2}>$ - and $\{11 \overline{2}\}<111>$-type (both generate $\Sigma 3$-type twin boundaries) have been observed. Interface-activated twinning processes based upon the core dissociation of interfacial dislocations: $1 / 6[\overline{1} 2 \overline{1}]_{(111)} \rightarrow 1 / 6[011]_{(100)}+1 / 6[\overline{1} 1 \overline{2}]_{\left(\overline{1}_{11)}\right.}$ and $1 / 6[1 \overline{2} 1]_{(111)} \rightarrow{ }_{-}\left[0 \overline{1}_{0}\right]_{(001)}+1 / 6[111]_{(11 \overline{2}), \text { and the }}$ emission of $1 / 6<\overline{1} 1 \overline{2}>$ and $1 / 6<111>$ twinning dislocations are proposed to rationalize the formations of $(\overline{1} 11)[\overline{1} 1 \overline{2}]$ - and $(11 \overline{2})[111]$-type twins.

Acknowledgments - This work was performed under the auspices of the U.S. Department of Energy by University of California, Lawrence Livermore National Laboratory under contract No. W-7405-Eng-48.

\section{References}

1. J. N. Wang, A. J. Schwartz, T. G. Nieh, C. T. Liu, V. K. Sikka and D. R. Clemens, in Gamma Titanium Aluminides, ed. Y-W. Kim et al., TMS (Warrendale, PA), p. 949 (1995).

2. C.T. Liu, P. J. Maziasz, D.R. Clemens, J.H. Schneibel, V.K. Sikka, T.G. Nieh, J. Wright, and L.R. Walker, in Gamma Titanium Aluminides, ed. Y-W. Kim et al., TMS, Warrendale, 679 (1995).

3. C.T. Liu, J.H. Schneibel, P.J. Maziasz, J.L. Wright and D.S. Easton, Intermetallics 4 , p. 429 
(1996).

4. Z. Jin, R. Beals and T.R. Bieler, in Structural Intermetallics, ed. Darolia et al., TMS

(Warrendale, PA), p. 275 (1993).

5. L. M. Hsiung and T. G. Nieh, Scripta Mater. 36, p. 323 (1997).

6. Z. Jin and T. R. Bieler, Phil. Mag. A 71, p. 925 (1995).

7. L.M. Hsiung and T.G. Nieh, Intermetallics, 7 (1999), 821.

8. J. N. Wang, A.J. Schwartz, T.G. Nieh and D.R. Clemens, Matls. Sci. \& Engrg. A206, p. 63 (1996).

9. J.W. Christian and S. Mahajan, Prog. Matls. Sci. 39, p.1 (1995).

10. L.M. Hsiung and T.G. Nieh, Matls. Sci, \& Engrg. A239-240, p. 438 (1997).

11. J.W. Edington, Practical Electron Microscopy in Materials Science, Van Nostrand Reinhold, New York, 1976.

12. C.T. Forwood, L.M. Clarebrough, Electron Microscopy of Interfaces in Metals and Alloys, Bristol: Adam Hilger (1991).

13. L. M. Hsiung, A. J. Schwartz and T. G. Nieh, Scripta Mater. 36, p. 1017 (1997).

14. E. Arzt, M.F. Ashby and R.A. Verrall, Acta Metall. 31, p. 1977 (1983).

15. J. Weertman, J. Appl. Phys. 28, p. 1185 (1957).

16. S.C. Huang and J.C. Chesnutt, in Intermetallic Compounds: Principles and Practice 2, ed. J. H. Westbrook and R. L. Fleischer, John Wiley \& Sons, p. 73 (1995).

17. J.D. Eshelby, F.C. Frank and F.R.N. Nabarro, Phil. Mag., 42, p. 351 (1951).

18. J.G. Wang, L.M. Hsiung and T.G. Nieh, Scripta Mater. 39, p. 957 (1998). 